\title{
Unidade de ensino potencialmente significativa para a abordagem do sistema respiratório humano: estudo de caso
}

Cleci Teresinha Werner da Rosa cwerner@upf.br

000-0001-9933-8834

versidade de Passo Fundo, Passo Fundo, Rio Grande do Sul, Brasil.

Juliano Cavalcanti uliano@upf.br

0000-0001-6636-5668 Universidade de Passo Fundo, Passo Fundo, Rio Grande do Sul, Brasil.

Carlos Ariel Samudio Perez samudio@upf.br

0000-0002-1976-9886

Universidade de Passo Fundo, Passo Fundo, Rio Grande do Sul, Brasil.

\section{RESUMO}

Um dos maiores desafios para os professores atualmente é desenvolver metodologias que instiguem nos alunos o desejo por aprender. Por conta disso, observa-se um movimento de educadores e pesquisadores em busca da qualificação do processo de ensino e de aprendizagem em Ciências, especialmente no ensino fundamental. Em vista dessa necessidade, somada à percepção de que as metodologias utilizadas no ensino dessa componente curricular estão surtindo pouco efeito como favorecedoras na apropriação dos conteúdos, o presente estudo teve como intuito conceber, desenvolver e avaliar uma proposta didático-metodológica apoiada na teoria cognitivista de Ausubel. Especificamente, foi elaborada uma Unidade de Ensino Potencialmente Significativo (UEPS) para o tema "sistema respiratório" nos anos finais do ensino fundamental, de modo a analisar a pertinência da proposta em termos de sua viabilidade enquanto estratégia didática. Os resultados do estudo indicam a viabilidade da proposta, especialmente em termos da sua potencialidade para o envolvimento e questionamento dos alunos.
\end{abstract}

PALAVRAS-CHAVE: UEPS. Teoria da Aprendizagem Significativa. Ensino fundamental II. Sistema Respiratório. 


\section{INTRODUÇÃO}

A sociedade atual vive momentos em que avanços significativos surgem na ciência e na tecnologia no dia a dia. Os resultados destes avanços são rapidamente revertidos em benefícios desta sociedade. Neste sentido, a educação não pode permanecer inerte, ela deve evoluir num ritmo que acompanhe as mudanças sociais e científicas. Isso é mais um desafio que a educação brasileira deve enfrentar. Evidentemente o desafio não é só das autoridades governamentais e especificamente das dá educação, que normalmente buscam soluções atualizando leis e políticas educacionais. Mas, é dos professores que devem estar atentos a processos de formação que Ihes permita atualizar e ampliar o seu conhecimento, assim como se capacitar para utilizar e até gerar novas ferramentas e técnicas de ensino que sejam eficientes para tornar possível a realização da sua prática docente que, deve estar sempre voltada às necessidades e anseios dos estudantes e da comunidade escolar.

No ensino de ciências é fato comprovado que os alunos enfrentam grandes dificuldades de aprendizagem, isto é comprovado pelo elevado número de reprovações nos diferentes níveis escolares, especialmente se considerarmos o ensino de Física. As causas deste problema não estão devidamente identificadas, mas existem possíveis razões que podem justificar o alto índice de fracassos dos alunos (ALMEIDA, 2001). Entre estas, se pode atribuir aos professores o uso de métodos de ensino desajustados das teorias de aprendizagem atualizadas. De fato, é amplamente sabido que na maioria das instituições de ensino brasileiras os conteúdos de ciências vêm sendo ensinados de forma tradicional, via transmissão e memorização de conhecimentos científicos, o que muitas vezes repercute numa aprendizagem mecânica e não significativa, levando assim a que o processo de ensino e aprendizagem não atinja o seu objetivo principal.

No ensino de forma tradicional o professor assume o status de principal agente do processo. Ele é quem administra as aulas expositivas, elabora e resolve problemas e exercícios de aplicação (MOREIRA, 2000). Mesmo utilizando recursos audiovisuais e atividades experimentais, o professor permanece elemento ativo na sala de aula. Seguindo esta estratégia, o papel dos alunos fica restrito à recepção e armazenamento de informações. Para Rosa e Rosa (2012): "O sistema educacional brasileiro, em particular o ensino de Ciências (Física), encontra-se em vias de colapso, deixando clara a inviabilidade de continuar privilegiando a transmissão dos saberes e o acúmulo de informações que a escola privilegiou" (p.1).

As autoridades governamentais reconhecem que a disciplina de Ciências no ensino fundamental desempenha um relevante papel no processo de formação dos jovens, e enfatizam nos Parâmetros Curriculares Nacionais (PCNs) que é essencial considerar o desenvolvimento cognitivo dos estudantes, relacionado a suas experiências, sua idade, sua identidade cultural e social, e os diferentes significados e valores que as Ciências Naturais podem ter para eles, para que a aprendizagem seja significativa (BRASIL, 1998, p. 27). Especificamente, para o terceiro e quarto ciclos do ensino fundamental os PCNs (BRASIL, 1998), apontam que em termos pedagógicos o professor deve estruturar didaticamente suas aulas de Ciências Naturais, pautado no "planejamento de unidades e projetos, visando 
sistematização de conhecimentos" (p. 115). Pretende-se que o planejamento, composto por unidades ou projetos para abordagem de temas, forneça melhores condições ao processo de aprendizagem, delineando as etapas e situações nas quais se quer submeter uma hipótese à prova, tendo como objetivo a construção dos conceitos e a aprendizagem. A integração dos conteúdos permite alimentar a possibilidade de que o professor proponha aos alunos situações significativas, presentes nas suas vivências, e que possibilitem explorar os temas transversais. A problematização, por sua vez, visa despertar no aluno o senso crítico frente às suas dificuldades, à dificuldade das pessoas que estão no seu entorno, bem como o engajamento em buscar no conhecimento alternativas que possam saná-las.

Os PCNs para a Área de Ciências Naturais apontam a necessidade de se utilizar, no contexto escolar, atividades que envolvam a busca de informações em fontes variadas, essas atividades permitem ir além da obtenção de informações para a elaboração/reelaboração de suas ideias e atitudes, promovendo "o desenvolvimento de autonomia com relação à obtenção do conhecimento" (BRASIL, 1998, p. 121). Nessa compreensão, são entendidos como modalidades desse procedimento "a observação, a experimentação, a leitura, a entrevista, a excursão ou estudo do meio e o uso de informática, por exemplo" (BRASIL, 1998, p. 121).

Reconhecida a importância do ensino de Ciências e tendo em consideração os constantes desafios que os professores devem enfrentar para atingir os objetivos do seu ensino, torna-se evidente a necessidade de que os professores possuam a sua disposição ferramentas didáticas (ou métodos de como construi-las) que lhes permitam atingir as metas do processo de ensino e de aprendizagem. Em virtude disto, o presente trabalho propõe a concepção, desenvolvimento e a avaliação de uma sequência didática na forma de Unidade de Ensino Potencialmente Significativa (UEPS). Dessa forma, o objetivo do texto do presente artigo é apresentar os fundamentos das UEPS, construir uma sequência didática para o ensino de um tema específico de Ciências Naturais, colocá-la em prática em sala de aula e avaliar as suas potencialidades. É importante destacar que uma pesquisa previa, efetuada pelos autores, mostra que essa opção estratégica para o ensino de conteúdos de Ciências Naturais não tem sido explorada na literatura nacional, o que justifica o presente estudo.

\section{Unidade de Ensino Potencialmente Significativa}

A UEPS, segundo Moreira (2011), é uma sequência de ensino direcionada à aprendizagem significativa de conceitos e tópicos específicos de um ou mais conteúdos escolares. A tese central é que os materiais e recursos utilizados estejam voltados a uma aprendizagem significativa na perspectiva de David Ausubel.

Para tanto, deve-se iniciar pela escolha do tema, dos recursos e dos materiais, que precisam ser potencialmente significativos para os alunos. Em outras palavras, a sequência didática elaborada pelo professor precisa considerar em sua estrutura o apregoado pela Teoria da Aprendizagem Significativa. Contudo, Moreira (2011) elenca, nos fundamentos da UEPS, características de outras teorias relacionadas à aprendizagem cognitiva, como as propostas por Novak, Vergnaud, Vygotsky, Gowin, Johnson-Laird e Moreira. 
Disso resulta um conjunto de princípios que o autor escolhe como fundamentais para a elaboração das UEPS e que podem ser assim sintetizados: a) a variável que mais influencia a aprendizagem significativa é o conhecimento prévio do aluno; b) os estudantes precisam apresentar sentimentos positivos em relação à aprendizagem, que, por sua vez, deve estar direcionada a ser significativa e crítica, e não mecânica e memorística; c) o aluno é quem decide se quer aprender significativamente determinado conhecimento; d) a relação entre os conhecimentos prévios e os novos conhecimentos é efetivada por meio de organizadores prévios, que podem ser as situações problemas propostas pelo professor; e) elas são organizadas pelo professor e dão sentido aos novos conhecimentos, além disso, devem ser criadas de forma crescente de dificuldade e despertar no aluno o desejo pela aprendizagem; f) uma nova situação de aprendizagem deve ser direcionada a que os alunos inicialmente construam seus modelos mentais; g) em uma estrutura de ensino, é necessário estarem presentes a diferenciação progressiva, a reconciliação integradora e a consolidação, conforme proposto por Ausubel; h) a avaliação da aprendizagem significativa é progressiva e deve ser feita em termos de buscas de evidências; e i) a interação social e a linguagem são fundamentais para a compreensão de significados, cuja essência está na relação entre aluno, professor e materiais educativos, podendo incluir-se aí o computador como um quarto elemento. A interação social nessa proposta ganha relevância e é entendida por Moreira (1999, p. 112) como “[...] veículo fundamental para a transmissão dinâmica (de inter para intrapessoal) do conhecimento social, histórica e culturalmente construído".

Moreira (2011) organizou tais princípios em etapas, que passam a sustentar a estrutura de uma UEPS e estão assim identificadas e sintetizadas:

1. Definição do tópico a ser abordado dentro das especificidades que a disciplina exige, inclusive com seus aspectos declarativos e procedimentais.

2. Criação de situação que leve o aluno a resgatar e expor seu conhecimento prévio, supostamente vinculado ao tópico em pauta (mapas mentais, mapas conceituais, situações problemas, questionário, debate, etc.).

3. Proposição de uma situação problema em nível introdutório do conteúdo e que sirva de referência para a discussão do novo. A situação problema deve ser tal que convenha apenas para resgatar e ancorar o novo conhecimento, sem, contudo, expô-lo na íntegra. Tais situações problemas podem funcionar como organizadores prévios e têm por objetivo dar sentido ao novo e possibilitar o estabelecimento de modelos mentais, de representações na mente do estudante. Moreira (2011), ressalta que esse momento encontra-se associado aos operadores invariantes, conhecimentos contidos nos esquemas, que, por sua vez, representam uma organização da conduta para uma certa classe de situações (atividades experimentais, demonstrações, vídeos, simulações, filmes, etc.).

4. Exposição do conteúdo objeto do estudo, levando em conta a diferenciação progressiva na perspectiva de Ausubel. Ou seja, a abordagem do conteúdo deve iniciar pelos aspectos mais gerais, incluindo exemplos de aplicação, até chegar ao aprofundamento do conteúdo. Moreira (2010) menciona que a diferenciação progressiva é um princípio programático no qual as ideias mais gerais e inclusivas do conteúdo devem ser apresentadas de forma a gradativamente ir detalhando e especificando. Continua o autor (2010, p. 5) ressaltando que: "Não se trata de um enfoque dedutivo, mas sim de uma abordagem na qual o que é mais relevante 
deve ser introduzido desde o início e, logo em seguida, trabalhado através de exemplos, situações e exercícios".

5. Apresentação de uma síntese envolvendo os aspectos mais gerais e estruturantes do conteúdo. Nesse momento, como mencionado por Moreira (2011), deve-se considerar o conteúdo em um nível de complexidade maior, envolvendo situações problemas com grau maior e crescente de complexidade, incluindo novos exemplos e promovendo a reconciliação integradora, conforme proposto por Ausubel. Essa, por sua vez, na perspectiva cognitivista, representa os novos significados que o aluno irá adquirir, fruto da interação ou combinação dos já existentes com os que estão sendo explorados.

6. A conclusão da unidade de ensino deverá proporcionar a continuidade no processo de diferenciação progressiva, de modo a retomar as características mais relevantes do conteúdo em questão, porém, de uma perspectiva integradora, ou seja, buscando a reconciliação integrativa. Acerca da reconciliação integrativa, Moreira (2010, p. 5) menciona que, na programação do conteúdo escolar, devemse possibilitar momentos para "explorar, explicitamente, relações entre conceitos e proposições, chamar a atenção para diferenças e semelhanças e reconciliar inconsistências reais e aparentes".

7. A avaliação da aprendizagem deve ser contínua, somativa e individual, estando relacionada a todas as ações desenvolvidas pelos alunos durante a implementação da UEPS. Essa avaliação deve conter questões que impliquem compreensão, que evidenciem captação de significados e, idealmente, alguma capacidade de transferência.

8. A avaliação da UEPS deve ocorrer mediante análise do desempenho dos alunos e de indícios de que ocorreu uma aprendizagem significativa. Moreira destaca que a aprendizagem significativa é progressiva, portanto, nessa etapa, o objetivo é a busca de evidências, e não de comportamentos finais.

Os passos apresentados de forma não tão rígida, mas oportunizando incorporar novas situações problemas, proporcionando que o professor faça suas adequações, têm sido utilizados como forma de subsidiar a abordagem de temas no ensino de Física, Química e Biologia. A proposta de UEPS apresentada neste trabalho visa abordar o tema de Ciências Naturais, Sistema Respiratório com alunos do oitavo ano do ensino fundamental.

\section{Estrutura e desenvolvimento da UEPS}

A proposta a ser apresentada toma por referência a realidade das escolas públicas, na qual a disciplina de Ciências integra a grade curricular com três períodos semanais e o conteúdo de Sistema Respiratório consta da programação do nono ano do ensino fundamental.

A elaboração da UEPS segue os pressupostos estabelecidos por Moreira e foi estruturada na forma de encontros nos quais são desenvolvidas atividades cuidadosamente planejadas. O Quadro 1 apresenta a distribuição das atividades na forma de encontros, destacando as etapas da UEPS contempladas em cada um. 
Quadro 1. Cronograma de encontros, etapa da UEPS abordada e as atividades a serem realizadas durante a aplicação da UEPS.

\begin{tabular}{|c|c|c|}
\hline Encontros & Etapa da UEPS & Atividades/Ações \\
\hline 1 & $\begin{array}{l}\text { Apresentação da proposta aos } \\
\text { alunos }\end{array}$ & $\begin{array}{l}\text { - Relato da proposta didática estruturada } \\
\text { - Encaminhamentos com os alunos } \\
\text { - Apresentação do tema em estudo } \\
\text { - Leitura de microtextos }\end{array}$ \\
\hline 2 & $\begin{array}{l}\text { Resgate dos conhecimentos } \\
\text { prévios }\end{array}$ & $\begin{array}{l}\text { - Trabalho com gravura referente ao caminho } \\
\text { do ar no corpo humano e às partes fisiológicas } \\
\text { envolvidas }\end{array}$ \\
\hline 3 & $\begin{array}{l}\text { Situação problema introdutória } \\
\text { - organizadores prévios }\end{array}$ & $\begin{array}{l}\text { - Questionamento introdutório: qual o caminho } \\
\text { do ar no corpo humano? } \\
\text { - Atividade experimental sobre medida do tórax }\end{array}$ \\
\hline 4 & Organizadores prévios & $\begin{array}{l}\text { - Atividade experimental relacionada à medida } \\
\text { do tempo entre a inspiração e a expiração }\end{array}$ \\
\hline 5 & $\begin{array}{l}\text { Abordagem do conteúdo } \\
\text { considerando a diferenciação } \\
\text { progressiva }\end{array}$ & $\begin{array}{l}\text { - Apresentação de forma expositiva e dialogada } \\
\text { - Realização de pesquisa utilizando livros } \\
\text { didáticos }\end{array}$ \\
\hline 6 & $\begin{array}{l}\text { Situação problema } 2 \text { (nível mais } \\
\text { complexo) }\end{array}$ & $\begin{array}{l}\text { - Apresentação de duas perguntas: qual a } \\
\text { função do diafragma? Como ele funciona? } \\
\text { - Realização de uma atividade experimental } \\
\text { para analisar o funcionamento do diafragma }\end{array}$ \\
\hline 7 & $\begin{array}{l}\text { Discussão do conteúdo } \\
\text { considerando a reconciliação } \\
\text { integrativa }\end{array}$ & $\begin{array}{l}\text { - Apresentação de forma expositiva e dialogada } \\
\text { - Apresentação em PowerPoint } \\
\text { - Apresentação de vídeos }\end{array}$ \\
\hline 8 & $\begin{array}{l}\text { Situação problema } 3 \text { (nível mais } \\
\text { complexo) }\end{array}$ & $\begin{array}{l}\text { - Apresentação de três perguntas: quais os } \\
\text { gases que compõem o ar? Quais os gases que } \\
\text { estão presentes na inspiração? E na expiração? } \\
\text { - Realização de uma atividade experimental } \\
\text { sobre a presença do gás carbônico no ar } \\
\text { expelido pelos pulmões }\end{array}$ \\
\hline 9 & $\begin{array}{l}\text { Discussão do conteúdo } \\
\text { considerando a reconciliação } \\
\text { integrativa }\end{array}$ & $\begin{array}{l}\text { - Apresentação de forma expositiva e dialogada } \\
\text { - Realização de pesquisa utilizando livros } \\
\text { didáticos }\end{array}$ \\
\hline 10 & Avaliação 1 & - Prova individual \\
\hline 11 & Avaliação 2 & - Encontro com profissionais da área de saúde \\
\hline 12 & Pós-UEPS & $\begin{array}{l}\text { - Correção da prova } \\
\text { - Doenças respiratórias } \\
\text { - Avaliação dos encontros }\end{array}$ \\
\hline
\end{tabular}

O planejamento proposto considera que cada encontro deve ter uma duração de uma hora/aula e incluiu três situações problemas, e não duas, como indicado na proposta de Moreira (2011). Tal necessidade teve como justificativa a extensão do conteúdo a ser tratado, porém, o acréscimo seguiu os mesmos passos indicados pelo autor, ou seja, uma situação com nível mais complexo de dificuldade e organizada de modo a possibilitar a reconciliação integrativa.

Para a aplicação da UEPS, selecionou-se uma turma de oitavo ano, de uma escola pública do município de Passo Fundo, composta por dezenove alunos. Na grade curricular, são destinados três períodos semanais à disciplina de Ciências. descrição dos encontros na forma de relato de ações, sempre, priorizando os 
aspectos metodológicos, sem fazer uma ênfase aprofundada dos conteúdos abordados. Todos os materiais de apoio e orientações para a realização das atividades da UEPS encontram-se a disposição do público num blog hospedado na página web http://sistemarespiratorionaueps.blogspot.com.br/.

\section{Apresentação da proposta}

No primeiro encontro, a proposta foi apresentada aos alunos, que ouviram uma explanação sobre o significado da pesquisa da qual estavam sendo convidados a participar. Na sequência, abriu-se a oportunidade para questionamentos e formalizou-se a participação dos alunos mediante envio, para assinatura dos pais ou responsáveis, do Termo de Consentimento Livre e Esclarecido.

Encerrada essa conversa inicial, foi apresentado o tema de estudo - sistema respiratório -seguindo o programa da disciplina de Ciências. Como forma de iniciar a discussão, estabeleceu-se um diálogo com os alunos, na intenção de que comentassem sobre situações do cotidiano que envolve a respiração. As falas dos alunos foram sendo registradas no quadro, sem qualquer inferência no sentido de corrigi-las. Assim, de forma livre, eles apresentaram ideias e entendimentos sobre o tema, inclusive dúvidas e incertezas sobre problemas e doenças respiratórias, o que possibilitou obter um panorama do conhecimento e dos anseios da turma sobre o tema.

Ainda nessa aula, para instigar e fomentar esse levantamento dos conhecimentos prévios, três microtextos, (A influência da respiração no corpo humano. Pressão: altos e baixos; A respiração adequada melhora o rendimento do atleta; e OMS diz que poluição atmosférica mata oito milhões de pessoas por ano, material disponível no blog) - foram entregues aos alunos, para que, organizados em duplas, procedessem à sua leitura e discussão. Houve, então, novamente, o registro no quadro das contribuições de cada grupo, fomentando a discussão no âmbito coletivo da sala de aula. $O$ objetivo dessa parte da atividade foi demonstrar a importância e amplitude do tema, identificando os conhecimentos prévios dos alunos, bem como despertando a sua curiosidade sobre o assunto. Ao final, efetuou-se a retomada dos aspectos levantados na aula e solicitou-se que o assunto fosse discutido com os familiares, para que novas questões pudessem ser levantadas.

\section{Resgate dos conhecimentos prévios}

No segundo encontro, para resgatar os conhecimentos prévios dos alunos, desenvolveu-se uma atividade relacionada à identificação dos caminhos do ar no organismo humano. No início da aula, solicitou-se que os alunos comentassem o diálogo estabelecido sobre o tema em estudo com seus familiares. O objetivo estava em "plantar" a curiosidade na forma de conhecimentos prévios, incentivando-os a buscarem respostas e ficarem atentos às atividades programadas para as próximas aulas.

A atividade desenvolvida nesse encontro visou retomar os conhecimentos que, em princípio, integram o programa de Ciências nos anos iniciais sobre o sistema respiratório. Para tanto, foi entregue aos alunos uma figura com esboço 
diferentes cores, as partes que o constituem. A figura utilizada não apresentava o nome dessas partes.

Como encerramento da aula, houve uma discussão acerca da figura, reservando-se para o encontro seguinte a discussão sobre os nomes das partes que integram o sistema respiratório.

\section{Situação problema 1 (organizadores prévios)}

O terceiro encontro foi marcado pela necessidade de estabelecer os organizadores prévios para a atividade. De acordo com Moreira (2011), ao se iniciar um tópico e resgatar os conhecimentos anteriores, poderá ser necessário criar pontes para ancorar os novos conhecimentos e, para isso, o autor sugere o estabelecimento dos organizadores prévios.

Nesta UEPS, os organizadores prévios foram estruturados em um questionamento inicial seguido de duas atividades experimentais. 0 questionamento ("Qual o caminho do ar no corpo humano?") teve por objetivo inserir o estudante no tema, de forma a oportunizar a estruturação de um modelo mental que subsidiasse o conteúdo que seria aprofundado nos demais encontros. Para tanto, retomou-se o material trabalhado na aula anterior e, com auxílio de uma gravura igual à dos alunos, projetada no quadro, identificou-se o caminho do ar, bem como as partes pertencentes ao sistema respiratório, com seus respectivos nomes. Destaca-se que a atividade foi colaborativa, uma vez que os alunos participaram e fizeram inferências sobre a nomenclatura.

Na sequência, foi realizada a primeira atividade experimental (Medida do perímetro torácico), cujo objetivo estava em medir as dimensões do tórax ou caixa torácica de cada aluno. Em duplas, os alunos mediram o perímetro da caixa torácica, com o auxílio de uma trena. Solicitou-se que fizessem duas medidas em situações diferentes, na inspiração máxima, cujo perímetro é máximo, e na expiração máxima, cujo perímetro é mínimo. Os valores foram sendo organizados em uma tabela no quadro, e todos os alunos fizeram o registro no caderno.

\section{Organizadores prévios}

A aula iniciou com o professor indagando os alunos sobre o assunto abordado no encontro anterior. Na continuidade, foi realizada outra atividade experimental (Frequência respiratória). A atividade consistiu em medir o tempo entre a inspiração e a expiração.

Para finalizar a aula, foi enfatizado o significado dos valores encontrados na atividade experimental, entre os quais se estabeleceu uma comparação. Aqui, é importante destacar que os alunos participaram e indagaram sobre as diferenças nos valores; inclusive, um aluno mencionou que, "por ser de baixa estatura, o valor entre sua inspiração e expiração seria igualmente menor do que o valor entre a inspiração e a expiração de alguém mais alto". Tal ideia foi refutada por um dos alunos, o qual imediatamente comparou dois valores expostos no quadro que eram próximos e que correspondiam a alunas com diferentes alturas. 
Nesse encontro, o objetivo foi aprofundar o entendimento dos alunos sobre o caminho do ar, que havia sido abordado de forma introdutória nos encontros anteriores. De acordo com a proposta de Moreira (2011), uma vez trabalhadas as situações iniciais, pode-se "apresentar o conhecimento a ser ensinado/aprendido, levando em conta a diferenciação progressiva" (p. 4). Diante disso, a opção foi por recapitular com os alunos as partes que integram o sistema respiratório, agora utilizando a percepção física decorrente das duas atividades experimentais realizadas. A seguir, foi proposta uma atividade na qual os alunos, reunidos em pequenos grupos, deveriam recorrer ao uso do livro didático para pesquisar o tema.

O tema pesquisado envolveu os seguintes aspectos: os caminhos do ar, os órgãos, cavidades nasais, faringe, epiglote, laringe, traqueia, pleura, pulmões, brônquios, bronquíolos, diafragma, músculos intercostais e alvéolos, que compõem o sistema respiratório, bem como as funções de cada um. O registro foi feito no caderno dos alunos e a discussão sobre o pesquisado foi realizada de forma verbal, no coletivo do grande grupo.

\section{Situação problema 2}

A sexta aula iniciou com uma breve exposição dialogada sobre o conteúdo estudado no último encontro. Assim, foram discutidas as funções de cada parte do sistema respiratório, utilizando os registros realizados pelos alunos na sua pesquisa. Com base nas respostas, e considerando a necessidade de que uma nova situação problema seja introduzida em nível mais alto de complexidade (MOREIRA, 2011), um novo questionamento foi apresentado aos alunos: qual a função do diafragma? Como ele funciona?

Como forma de iniciar as discussões sobre o funcionamento desse músculo, foi proposta uma atividade experimental (Pulmão de garrafa pet) na qual os alunos construíram um dispositivo que simula o funcionamento do diafragma no corpo humano. Para tanto, seguindo as instruções do material distribuído pelo professor, utilizaram materiais alternativos que Ihes haviam sido previamente solicitados, tais como balões, garrafas pet, fita adesiva, tesoura, entre outros. Após essa tarefa, cada grupo buscou elaborar explicações sobre o funcionamento do seu aparelho e, consequentemente, do diafragma.

A atividade experimental visou, basicamente, ilustrar como ocorre a inspiração e a expiração do ar nos pulmões, oportunizando questionamentos por parte dos alunos, tais como: o diafragma contrai na expiração ou na inspiração? Qual a forma correta de respirar? Fazer com que o ar entre pelo nariz e saia pela boca é melhor do que respirar só pela boca? Na corrida, às vezes sentimos dores na barriga. É o diafragma que dói? A asma é um problema no diafragma? Quando eu soluço, a minha barriga mexe sozinha. É o diafragma que faz isso? É por isso que ser barrigudo faz mal? Quando a gente espirra, a barriga aperta. É bem ali que se localiza o diafragma?

Após as discussões, e para finalizar a aula, foi proposta aos alunos uma atividade física que visava levá-los a perceber a presença do diafragma no próprio corpo. Em pé, todos colocaram a mão sobre o diafragma e, posteriormente, 
Esse encontro visou promover situações que permitissem ao aluno conectar os conhecimentos, considerando o processo de diferenciação progressiva, mas retomando as características mais relevantes do conteúdo em questão, dentro de uma perspectiva integradora, ou seja, buscando a reconciliação integrativa (MOREIRA, 2011).

O conteúdo selecionado foi respiração celular, no qual foram retomadas e contextualizadas as partes do sistema respiratório e suas funções, bem como a importância do diafragma dentro desse contexto. Para tanto, contou-se com o apoio de slides e vídeos (disponíveis no blog) para ilustrar os caminhos do ar, o funcionamento do diafragma e a respiração celular. A apresentação dos slides serviu para contemplar imagens sobre os caminhos do ar, os brônquios, os bronquíolos e os alvéolos pulmonares, assim como as trocas gasosas, a difusão e o movimento do oxigênio e do dióxido de carbono no sangue. O aumento da umidade e temperatura do ar na faringe e laringe e a expulsão de materiais estranhos, juntamente com o funcionamento da epiglote, foram igualmente demonstrados. Ainda, observou-se a posição do diafragma na inspiração e expiração, além dos músculos intercostais.

Como forma de finalizar a aula, oportunizou-se aos alunos que manifestassem suas conclusões sobre os vídeos e o que levariam da aula para suas vidas. Esse momento se revelou importante para verificar como os alunos estavam interagindo com o conteúdo e com a proposta metodológica em análise.

\section{Situação problema 3}

O conteúdo a ser abordado guiado por situações problemas, como propõe Moreira (2011), deve ser gradativamente ampliado, refinando-se. Dessa forma, o oitavo encontro foi guiado pela apresentação de três perguntas cujo objetivo esteve em discutir a presença do dióxido de carbono na expiração. Para tanto, foram feitos os seguintes questionamentos: quais os gases que compõem o ar? Quais os gases que estão presentes na inspiração? E na expiração? Para subsidiar os alunos na construção de suas repostas, foi realizada uma nova atividade experimental, cujo objetivo consistiu em demonstrar que o gás expelido pelos pulmões é o dióxido de carbono.

Para essa atividade experimental conhecida como "Sopra Mágico" os alunos foram organizados em grupos, sendo distribuído o material e discutido o procedimento de forma coletiva. A experiência desenvolvida permite visualizar como uma solução muda de cor ao entrar em com o gás expelido pelos pulmões e que essa mudança está diretamente relacionada à presença de gás carbônico.

$\mathrm{Na}$ continuidade, foram apresentados aos alunos, de forma dialogada e expositiva, os percentuais da composição gasosa na inspiração e na expiração, mostrando que o oxigênio entra em maior quantidade e sai em menor quantidade, enquanto que o gás carbônico sai em maior quantidade. A atividade experimental foi retomada no sentido de se esclarecer à turma o modo como o gás carbônico expelido pelos pulmões reage com a solução, alterando a sua cor. Nesse sentido, expelem o gás carbônico, que é um resíduo da troca gasosa ocorrida. 
Ao final do encontro, os alunos fizeram registros no caderno, procedendo a um fechamento da atividade realizada.

\section{Abordagem do conteúdo}

O objetivo desse encontro foi estabelecer a integração do saber abordado na aula anterior com os demais conteúdos, no sentido da reconciliação integrativa. Para tanto, a aula iniciou pela recuperação do discutido anteriormente, sobretudo em termos da atividade experimental efetuada. Os alunos tiveram a oportunidade de realizar novas perguntas a respeito, permitindo o estabelecimento de correlações entre os conteúdos que estavam sendo trabalhados.

Na sequência, e como forma de atingir o objetivo traçado, propôs-se aos alunos a realização de uma nova pesquisa nos livros didáticos, procedendo a registros no caderno. Essa pesquisa foi guiada por um conjunto de tópicos (ver blog) elencados com base nas dúvidas apresentadas. Além disso, foram propostas atividades de resolução dos exercícios do livro didático.

Ao final do encontro, os exercícios foram corrigidos e, em seguida, os resultados da pesquisa foram discutidos. Estes possibilitaram a abordagem de novos conceitos, como hematose, hemoglobina e glóbulos vermelhos, sobre os quais se passou a explanar com a turma. Essa atividade também serviu como revisão para a avaliação da aprendizagem, agendada para a aula seguinte.

\section{Avaliação 1}

A avaliação, que marcou o décimo encontro, representa, na proposta de Moreira (2011), o momento no qual se oportuniza aos alunos a demonstração individual de que o conhecimento foi adquirido. Contudo, o autor salienta que essa deve ser contínua e estar associada a todas as ações desenvolvidas pelos alunos durante a proposta didática, e não apenas ao finalizá-la. Ao mesmo tempo, valoriza em uma UEPS o momento em que os alunos são instigados a responder a questões/situações que impliquem compreensão e evidenciem captação de significados, além de alguma capacidade de transferência.

Partindo dessa premissa, a avaliação foi realizada de forma escrita, individual e organizada com nove questões discursivas e uma objetiva. Os conteúdos abordados na avaliação foram caminhos do ar, funcionamento do diafragma e respiração celular.

\section{Avaliação 2}

O último passo indicado em uma UEPS é a avaliação do conteúdo dentro de um contexto que complemente a avaliação somativa realizada na etapa anterior. Seu objetivo consiste em verificar evidências de uma aprendizagem significativa, o que possibilita considerar que a proposta didática foi exitosa. Contudo, sabe-se que tal aprendizagem significativa é de difícil percepção, ou, pelos menos, leva tempo para ser percebida. Nesse sentido, Moreira (2011) destaca que "a ênfase deve estar nas evidências, não em comportamentos finais". (p. 5) de existir um posto de saúde no prédio ao lado da escola. Assim sendo, foram 
convidados vários profissionais da área da saúde, integrantes da equipe do posto - um médico, duas enfermeiras, uma psicóloga e uma farmacêutica - para efetuarem um debate sobre o tema em estudo com os alunos. O diálogo estabelecido entre os participantes esteve basicamente centrado na discussão de causas de doenças respiratórias, cuidados com o sistema respiratório e vacinas. Além disso, os alunos tiveram oportunidade de esclarecer dúvidas sobre o uso de cigarro e, especialmente, de maconha.

Em termos metodológicos, o encontro, que teve a duração de dois períodos, foi estruturado de modo a possibilitar o espaço necessário para que os alunos interagissem com os profissionais da saúde através de comentários e/ou questionamentos sobre os temas tratados. Isto possibilitou efetuar uma avaliação qualitativa do diálogo dos estudantes que permitiu identificar manifestações que revelassem indícios da correta apropriação de conceitos estudados na sala de aula.

\section{Encerramento}

O último encontro teve como intuito a finalização das atividades com a turma. Nessa aula, a prova realizada no décimo encontro foi corrigida e também pôde ser abordado o tópico "doenças respiratórias", que havia sido discutido com a equipe multiprofissional da área de saúde, que no encontro anterior. Além disso, foi oportunizado aos alunos falar sobre a atividade desenvolvida durante os onze encontros, apontando suas percepções em relação à metodologia empregada.

\section{Avaliação da UEPS}

As UEPS primam pela diversificação de estratégias de aprendizagem, apostando na possibilidade de contribuir para o desenvolvimento das estruturas mentais do aluno, ao exigir-Ihe diferentes movimentos cognitivos. Diante desse contexto, e visando efetuar uma análise que permite-se identificar as potencialidades e dificuldades da presente proposta didática, paralelamente à verificação da postura do aluno diante da atividade, foi utilizado como instrumento de coleta de dados um diário de bordo elaborado pelo pesquisador, no caso o próprio professor da turma, após desenvolvimento de cada aula. Na perspectiva de Zabalza (2004), o diário de bordo constitui um espaço destinado a registros, anotações e reflexões individuais sobre um determinado processo de aprendizagem. Nele, é possível proceder a anotações relacionadas às experiências vivenciadas e observadas no contexto escolar, registrando todas as ações desenvolvidas e a movimentação dos estudantes durante a aula. Além disso, o diário possibilita o registro do olhar do pesquisador sobre a sala de aula e os alunos. Esse foi o intuito do presente estudo, no qual se recorreu ao diário de bordo como registro das ações para subsidiar a análise sobre a viabilidade da UEPS e verificar a existência ou não de indícios de uma aprendizagem significativa.

Destaca-se, que o objetivo central que conduz à utilização dessa ferramenta de avaliação consiste na sua possibilidade de contribuição com a sistematização didática e metodológica das atividades realizadas durante a execução da UEPS. Nesse sentido, para a discussão e análise dos dados, procede-se a eleição de categorias consideradas aqui como os aspectos estabelecidos a partir da aplicação (2011) elenca como fundamentais de uma UEPS. Os aspectos escolhidos são: 
conhecimentos prévios; diferenciação progressiva e reconciliação integrativa; interação social; e diversidade de estratégias.

Para a discussão dos resultados, recorre-se a esses aspectos, expondo inicialmente o seu entendimento e, a seguir, informações registradas no diário de bordo. A esse respeito, menciona-se que tais registros, quando descritos integralmente no texto, são destacados em itálicos e citados entre aspas.

\section{Conhecimentos prévios}

Inicia-se discorrendo sobre o papel do resgate dos conhecimentos prévios na apropriação do conhecimento e o modo como esse momento interferiu na operacionalização da UEPS.

A análise dos registros no diário de bordo permite concluir que a UEPS oportunizou diferentes momentos destinados ao resgate dos conhecimentos prévios, com destaque para os encontros iniciais, que buscaram ativar, na estrutura cognitiva dos estudantes, elementos que possibilitassem ancorar o tópico em estudo. Tais elementos estavam situados nos conhecimentos escolares anteriores, uma vez que o tema é abordado nos anos iniciais e está associado a conhecimentos do senso comum ou adquiridos fora da escola.

Os registros demonstram a importância desses conhecimentos prévios e a validade de serem favorecidos durante as aulas. Especialmente em termos da UEPS aplicada, tais momentos possibilitaram mostrar que os alunos apresentam conhecimentos quando chegam à escola, muitos deles equivocados, com falta de embasamento científico. Além disso, evidenciaram que os alunos apresentam dúvidas, de forma que, se lhes fosse dado o devido espaço, poderiam apresentar e discutir esses questionamentos.

A atividade realizada no segundo encontro da UEPS, por exemplo, na qual foi proposto que os alunos colorissem uma gravura, evidenciou que os conhecimentos escolares anteriores não estavam disponíveis e ao alcance da turma e que haveria necessidade de estruturá-los para que pudessem ancorar os novos. As dificuldades foram observadas no momento em que praticamente todos os alunos mencionaram a faringe, laringe, epiglote e traqueia como sendo a garganta, não distinguindo as partes mencionadas e que estavam destacadas na gravura.

Observou-se que as atividades programadas como forma de promover organizadores prévios funcionaram muito bem como pontes cognitivas entre o que o estudante já sabia e o que o professor, pesquisador, propõe como objetivo de aprendizagem. Em outras palavras, isto possibilita que o novo conhecimento seja aprendido de forma significativa.

Os momentos mais significativos em termos da importância da retomada dos conhecimentos anteriores e da expressão dos saberes pelos estudantes, revelaram-se no início de cada encontro, mediante o resgate do que havia sido abordado na aula anterior. Esse movimento cognitivo de recuperar informações é extremamente importante tanto para o planejamento das atividades como para a construção dos saberes por parte dos alunos. Destinar, em cada aula, um determinado tempo para retomar e esclarecer dúvidas do encontro anterior representa oportunizar um movimento cognitivo de recuperação da informação, 
como destacado por Rosa (2011), e constitui uma importante estratégia na busca pela aprendizagem significativa.

\section{Diferenciação progressiva e reconciliação integrativa}

O reconhecimento de que a aprendizagem dos novos saberes somente se torna significativa quando altera definitivamente os anteriores leva ao entendimento, de acordo com Ausubel (2003), de que os conteúdos escolares devem ser estruturados do geral para o específico. Isto é, devem-se apresentar inicialmente os conceitos mais gerais e, pouco a pouco, ir introduzindo os mais específicos (diferenciação progressiva). Na mesma direção, os conteúdos que inicialmente são apresentados de forma individualizada precisam, ao final, ser interligados, caracterizando-se suas semelhanças e diferenças dentro do contexto em estudo.

Sobre a necessidade da reconciliação integrativa durante a abordagem dos conteúdos em uma unidade de ensino, Palácios, Dal'Farra e Geller (2011), reportando-se ao pensamento de totalidade em Edgar Morin, afirmam que "é preciso ligar a totalidade com a inter-relação, a partir da ideia de organização, definida como o encadeamento de relações entre componentes produzindo uma unidade complexa, ou sistema, e formando um todo" (p. 215). Contudo, os autores enfatizam que ela ainda representa um grande desafio a ser enfrentado pelos professores para a realização de ações no âmbito do ensino de Ciências.

A análise dos registros mostra que todos os encontros da UEPS foram permeados pela estruturação dos conteúdos partindo desses dois aspectos considerados norteadores da proposta. A importância de começar pelos aspectos mais inclusivos do conteúdo foi salientada no diário de bordo no relato ao final do nono encontro: "Durante a atividade de pesquisa, a maioria dos alunos se mostraram envolvidos com a atividade e buscaram responder a todas as perguntas de forma completa. Eles buscaram no livro as respostas, mas também procuraram utilizar o conhecimento discutido de forma oral em sala de aula. Isso foi possível observar no momento em que me chamavam nos grupos e comparavam as respostas do livro com o que eu havia falado para eles."

Outro aspecto importante associado à utilização da diferenciação progressiva e da reconciliação integrativa enquanto elementos estruturais da unidade didática foi a distinção entre a metodologia empregada na proposta e a tradicionalmente presente no ensino dessa disciplina na escola. Organizar o conteúdo de modo que inicialmente fosse apresentado o conteúdo de uma forma mais geral, para detalhálo, gradativamente, a cada encontro e, ao final, promover uma integração desses saberes, pode colaborar para uma mudança de paradigmas do professor que costuma organizar, preparar e ministrar suas aulas de maneira tradicional. Neste estudo os resultados demonstram que este tipo de organização de conteúdos resultou numa mudança de pensamento do professor/pesquisador.

Embora tenha se mostrado interessante por possibilitar uma constante retomada nos conteúdos e, ao mesmo tempo, oportunizar que os estudantes esclarecessem dúvidas e apoiassem os conteúdos em conhecimentos anteriores, essa nova organização se revelou desafiadora em outros aspectos. Um dos 
vezes, houve dificuldades em planejar a aula de modo a partir de temas mais gerais para, então, ir desvelando as partes no decorrer das aulas subsequentes. $O$ registro do sexto encontro aponta essa dificuldade: "O programado para a aula era o estudo do diafragma, porém, o tempo necessário para a realização da atividade experimental, juntamente com abordagem do conteúdo, não permitiu que a aula ocorresse da forma planejada e no tempo de um período".

Observou-se que a dinâmica da sala de aula nem sempre possibilita que o professor tenha controle de todas as variáveis, especialmente em se tratando de proposta didática que envolve os estudantes de forma ativa. Além disso, o conteúdo a ser explorado, por vezes, exige a inclusão e discussão de elementos que retardam a execução do previsto em termos de proposta didática. Isso pode ser considerado um desafio da proposta didática em avaliação neste estudo.

Evidentemente, as dificuldades relatadas impõem um posicionamento do professor na hora de planejar as atividades didáticas. Este posicionamento remete à opção de lecionar de forma extensiva, ministrando todos os conteúdos no tempo disponível, o que possivelmente não permitirá o uso de diversas estratégicas didáticas e poderá culminar num ensino de pouca qualidade.

\section{Interação social}

Por interação social entendem-se as relações estabelecidas no contexto escolar entre os sujeitos envolvidos no processo, incluindo-se aí a interação desses sujeitos com o material didático. Moreira (2011, p. 3), ao fundamentar as etapas de uma UEPS, referenciando-se em Vygotsky, anuncia que "a interação social e a linguagem são fundamentais para a captação de significados".

Aprender implica estar com o outro, e esta interação leva a novas construções cognitivas. Portanto, em uma proposta didática que prima pela busca de uma aprendizagem significativa, duradoura e que proporcione desenvolvimento cognitivo, a interação social deve permear as ações. Na UEPS, é exatamente isso que ocorre, pois sua estrutura é constituída de tal forma que o diálogo entre aluno e professor, aluno e aluno e entre aluno e material didático é fundamental para sua efetivação.

Na UEPS desenvolvida neste trabalho, vários foram os momentos em que a interação social se mostrou presente e favorecedora da aprendizagem. Desde o primeiro encontro, o diálogo foi a tônica das ações propostas. Seja na forma de questionamentos ou de inferências, resgatando conhecimentos e mencionando relatos de situações vivenciais, os alunos participaram da aula e interagiram com o professor. $O$ relato ao final do segundo encontro demonstra essa interatividade: "Hoje os alunos questionaram muito e se mostraram interessados no tema. Houve perguntas de diferentes tipos, como as que buscavam apenas saber o que era laringite. Mas também houve os que queriam saber sobre maconha ou se uma pessoa que não fuma pode ter câncer de pulmão. As perguntas foram tantas que por vezes tinha que organizar a turma para poder ouvi-los."

Nesse quesito de proporcionar a interação social, a proposta didática se mostrou privilegiada, na medida em que houve outros momentos intensos em termos de trocas e diálogos, como as atividades experimentais, a pesquisa no livro 
estudantes que, por vezes, se mostravam mais retraídos e pouco interagiam passaram a indagar e discutir com seus colegas.

No oitavo encontro, foi realizada a atividade experimental para investigar os gases presentes no ar. $\mathrm{O}$ relato no diário de bordo desse encontro registra o entusiasmo dos alunos diante de suas observações: "Foi difícil conter os alunos durante a atividade, tamanho o deslumbramento deles com o que observavam. A aula foi um tumulto, e minha presença parecia pouco importante para eles, pois o importante era a magia do que estavam realizando. As respostas para o que era observado demoraram a serem discutidas, pois o mais importante eram as inferências que eles faziam, mesmo que na maioria equivocadas."

Já em relação à pesquisa com o uso do livro didático, a qual ocorreu em dois momentos, destaca-se que, em proporções diferentes da verificada nas atividades experimentais, essa tarefa proporcionou uma importante interação, na forma de troca entre os alunos do grupo. Sua importância esteve em possibilitar que, no diálogo das duplas de trabalho, um aluno auxiliasse o outro em suas dificuldades.

A interação ocorrida no décimo primeiro encontro, no qual participaram os profissionais da saúde, pode ser considerada de grande intensidade. Por certo que o tema e a oportunidade de realizar perguntas a peritos no assunto levaram a que os estudantes se sentissem estimulados a isso. Porém, os debates realizados nos encontros anteriores, somados à liberdade de pesquisar e dialogar, que lhes foi assegurada durante toda a proposta, forneceram aos estudantes os elementos necessários para interagirem com os profissionais presentes em sala de aula. $\mathrm{O}$ relato desse encontro complementa o exposto: "Desde o momento da apresentação dos profissionais até o início do debate, era notória a curiosidade e a ansiedade dos alunos em poderem demonstrar os conhecimentos apreendidos e principalmente se sentirem bem ao discutirem um assunto. Os alunos se prepararam e queriam muito aquele momento, sempre perguntando ao professor quando este dia chegaria. Quando chegou foi bem interessante, pois os profissionais tiveram trabalho para atenderem todas as perguntas e em alguns momentos houve a necessidade estabelecer uma ordem das perguntas e respostas dos alunos, que por ora queriam contribuir expressando aquilo que já sabiam sobre os assuntos. Por fim, a atividade se mostrou mais como um debate que constantemente ia sendo interrompido por novas dúvidas ou contribuições dos colegas. O ambiente da aula foi do início ao fim de muita cordialidade de ambas as partes, mostrando assim a colaboração e o empenho ao realizar a atividade."

\section{Diversidade de estratégias}

A diversidade de estratégias é apontada por Moreira (2011, p. 5) como aspecto transversal à proposta: "em todos os passos, os materiais e as estratégias de ensino devem ser diversificados". Nesse sentido, ao estruturar a UEPS, buscouse, de um modo geral, diversificar as estratégias, recorrendo a vídeos, slides, atividades experimentais, textos, livro didático e uso de questionamentos.

Cada estratégia de ensino tem seu potencial e seus limites, como foi registrado no diário de bordo em diferentes encontros: "Na aula de hoje foram utilizados alguns vídeos de curta duração que traziam imagens reais sobre o sistema respiratório. Ao mesmo tempo em que alguns alunos se mostraram entusiasmados com os vídeos, outros solicitaram que parassem de passar as imagens, pois 
estavam perplexos com as imagens. Um aluno ficou estarrecido e disse jamais imaginar que dentro do nosso corpo fosse assim. Outro ficou surpreso ao ver que a traqueia tinha formato de anéis sobrepostos."

O uso de vídeos com imagens reais no ensino da Biologia pode provocar desconforto e, não raro, até dificultar o entendimento, devido aos sentimentos que são estimulados no aluno. A reação dos estudantes ao assistirem ao vídeo não foi unânime, tampouco previsível. Um deles, inclusive, solicitou que o professor adiantasse uma das cenas para não vê-la. Fatos como esse, por vezes, fogem do alcance do professor, que acaba tomando conhecimento das limitações e dificuldades dos alunos no momento da execução da atividade. Todavia, a sua sensibilidade e o seu saber pedagógico devem mostrar o caminho a ser seguido, sem expor os estudantes a situações de desconforto.

Ainda em termos da potencialidade da atividade na interação social, destacase o registrado pelo professor: "Cada vez que falo que vou fazer uma atividade experimental eles se mostram entusiasmados. Será essa uma boa estratégia para mantê-los atentos à aula? Poder movimentar o corpo, sair de sua classe e conversar com o colega leva a uma maior participação e ao envolvimento dos alunos?"

Tal registro remete à possibilidade de que as aulas de Ciências sejam estruturadas de forma a envolverem mais atividades em que os estudantes sejam ativos no processo - ativos intelectual e fisicamente, pois se sabe de todas as dificuldades e do desgaste do professor para manter seus alunos atentos e limitados ao espaço de suas classes.

O uso das atividades experimentais no ensino de Ciências é amplamente defendido por professores e pesquisadores da área (ARRUDA, 1998; PINHO-ALVES, 2000; BORGES, 2002). Rosa (2001), na mesma direção, salienta o fato de que o abuso dessa estratégia pode, no entanto, ser mais prejudicial do que sua ausência na aprendizagem. Muitas vezes, destaca a autora, os professores acabam forçando situações experimentais apenas com o intuito de usá-las, quando elas poderiam ser substituídas por uma imagem de vídeo ou mesmo por uma explicação teórica. A questão é mais saber quando e por que usar do apenas usar (ROSA, 2011).

Em outro registro, é possível verificar que os alunos se mostraram participativos e receptivos à estratégia utilizada: "[...] o uso de perguntas no início da exposição do conteúdo levou a que os alunos olhassem o conteúdo de forma diferente. Eles estavam habituados a apenas copiar o que professor põe no quadro e hoje eles tiveram que pensar primeiro [...] alguns alunos se mostram incomodados, mas outros estimulados."

O uso de questionamentos é uma estratégia que tem ganhado espaço no ensino de Ciências. Lorencini (1995) destaca que a arte de fazer perguntas, quando utilizada pelo professor, pode ser um procedimento simples para estimular a atividade mental reflexiva do aluno e orientá-lo na busca pessoal do conhecimento. Nas palavras do autor (1995, p. 106): "A aula expositiva dialogada é uma possível alternativa para substituir a aula expositiva tradicional, transformando a sala de aula em um ambiente propício à reelaboração e produção de conhecimentos". 
Tal estratégia estimula o pensamento e possibilita um ambiente favorável aos alunos, proporcionando liberdade para expressar suas ideias, além de ofertar momentos de recuperação de seus conhecimentos em sua estrutura cognitiva.

\section{Considerações finais}

Dentre os objetivos do processo de ensino, está o de tornar as aulas de Ciências mais motivadoras e possibilitar que a aprendizagem dos conteúdos ocorra de forma significativa, ultrapassando a mera memorização de conceitos e fórmulas - o que é, sem dúvida, desafiador para o professor (ROSA, 2001). Para isso, tornase fundamental propor alternativas metodológicas que, pautadas em pressupostos teóricos, conduzam os alunos a uma compreensão de ciência capaz de lhes fornecer condições de melhor entenderem o mundo circundante e dele participarem de forma crítica e atuante.

Elaborar propostas metodológicas e avaliá-las em situações reais de ensino tem sido o desafio de educadores e pesquisadores que estão preocupados em ofertar um ensino mais significativo para os alunos. E foi partindo desse entendimento que o presente estudo se consolidou.

A proposta, pautada teoricamente na perspectiva cognitivista, especialmente no trabalho de Ausubel sobre aprendizagem significativa, mas não apenas nele, e traduzida como estratégia de ensino por Moreira, foi concebida, desenvolvida e analisada ao longo deste trabalho.

Nesse sentido, destaca-se que inicialmente foi efetuada uma pesquisa na literatura nacional que demonstrou que essa opção estratégica não tem sido explorada pelos investigadores, o que justifica o presente estudo. Na sequência, o foco passou a ser a sua estruturação para contemplar o item do conteúdo programático do ensino fundamental II em Ciências denominado de "sistema respiratório". Para tanto, o estudo propôs e implementou uma sequência didática envolvendo doze encontros, os quais foram guiados na perspectiva de proporcionarem uma aprendizagem significativa do conteúdo.

Ao avaliar-se a implementação dessa sequência didática, utilizando como instrumento de coleta de dados um registrada no diário de bordo, elaborado pelo professor, pesquisador neste caso, consideraram-se aspectos elencados por Moreira como norteadores de uma UEPS. Os resultados, apresentados em grupos apontaram que a proposta é viável em termos didáticos e favorece o processo de ensino-aprendizagem. Cada um dos grupos da análise apresenta elementos essenciais para a avaliação do professor e a tomada de decisão das ações a serem desenvolvidas em sala de aula. Além disso, os grupos fornecem subsídios metodológicos que otimizam o tempo e as atividades sem prejuízo na participação dos alunos e na interação com os colegas.

No grupo em que se analisam os resultados referentes ao aspecto "conhecimento prévio" ressalta o aproveitamento das ideias e dos contextos dos alunos por parte do professor pesquisador e dos colegas da turma. Após esse levantamento de dados e a discussão, são construídas as concepções da relação entre o aluno, o conhecimento e o professor. Para o aluno, a atividade se torna acolhedora, e as contribuições feitas pela turma de alunos transformam a sua concepção, ao mesmo tempo em que ele também transforma a concepção do professor. Para o professor, as ações a serem desenvolvidas são pautadas nessa 
transformação das concepções dos alunos, norteando as medidas a serem tomadas posteriormente na diferenciação progressiva e reconciliação integrativa por meio dessa interação social e da diversidade de estratégias.

No que se refere à "diferenciação progressiva e reconciliação integrativa" a análise dos registros destaca que apenas tratar de um assunto e discutir sobre ele não torna a aprendizagem significativa, pois o aluno precisa generalizar aquele conceito entendido, mas ainda não totalmente compreendido. Nesse momento, o papel do professor é ainda mais reforçado, para estimular o aluno a entender o que falta discutir, onde se aplica aquele determinado conceito e, assim, promover as condições para um fechamento, uma união das ideias frente ao assunto.

A utilização da "interação social", por sua vez, demonstra o benefício de promover uma aprendizagem que é mútua e produtiva, que não estabelece um monopólio de ideias e que coloca à prova tudo aquilo que os atores da aprendizagem já conhecem. Ambos os envolvidos alteram sua percepção frente ao outro, aprendem a respeitar as ideias, ora divergindo, ora convergindo, e muitas vezes discutindo. É o momento da divulgação das experiências, da contribuição, do engajamento em tornar o conhecimento algo que está fora do aluno, mas dentro do seu contexto. $O$ conhecimento acaba sendo elemento necessário para o entendimento do problema tratado.

A utilização da UEPS para o ensino de Ciências no ensino fundamental deve ser amplamente desenvolvida e disseminada. Proporciona dinâmica e robustez no desenvolvimento de um conteúdo, aguçando a curiosidade do aluno frente ao novo conceito, promovendo sua emancipação e reflexão sobre o seu cotidiano, formando um cidadão que aperfeiçoa a sua vivência e a das pessoas que o rodeiam. Mediante o conhecimento adquirido, descarta a mera memorização dos conceitos e potencializa a sua significação.

Os resultados demonstram que as principais dificuldades enfrentadas pelo professor pesquisador ao conceber a UEPS são o planejamento das ações, o uso de diferentes meios de busca das informações, o desconhecimento do tempo de desenvolvimento das atividades experimentais e a empatia do professor em relação à curiosidade e às experiências do aluno. São fatores igualmente limitantes o acesso aos recursos de informática, que muitas vezes são precários na rede de ensino, e a quantidade de alunos a serem atendidos durante uma atividade experimental. Em turmas muito numerosas, o professor deverá realizar os experimentos de forma mais demonstrativa para o grande grupo. Apesar das dificuldades de elaboração de uma UEPS, seus resultados e objetivos alcançados a tornam prazerosa por parte do professor, pois direciona seu trabalho para a principal finalidade da aprendizagem, que é tornar a vida das pessoas cada vez mais agradável, contribuindo para a ética e a cidadania, respeitando a si mesmo e aos outros.

Durante a implementação da UEPS, é de fundamental importância o professor estar ciente de que não terá respostas para todos os questionamentos e que muitos deles irão além do que fora planejado. Ele deve encarar essa metodologia como um documento norteador, que o auxiliará na busca das respostas. O professor se sente obrigado a saber as respostas para todas as perguntas, quando, na verdade, deveria aprender junto com os alunos. As experiências dos alunos e suas indagações devem ser aproveitadas, mesmo aquelas que a princípio não estabelecem uma relação direta com o assunto, sob pena de o aluno não se sentir 
seguro e acolhido e acabar se desestimulando, deixando de participar nas próximas atividades.

Num sistema de ensino onde os fracassos são cada vez mais evidenciados, seja em Matemática, Ciências ou qualquer outra área, buscar alternativas que se tornem bases fortes para a aquisição e construção do conhecimento é o papel do profissional em educação e, muitas vezes, um desafio. A formação continuada e o engajamento do professor em aceitar o desafio de ensinar e se colocar junto ao aluno para aprender são diferenciais no processo de ensino e aprendizagem, gerando benefícios para ambas às partes envolvidas. Para o professor e o aluno, o fazer pedagógico se torna eficiente e digno, pois é construído por eles, é algo para se motivar e se entusiasmar. Afinal, são agentes transformadores com diferentes funções, porém com o mesmo objetivo: aprender significativamente cada vez mais, e não apenas memorizar. 


\title{
Potentially meaningful teaching unit for the respiratory system approach: a case study
}

\begin{abstract}
One of the biggest challenges for teachers today is developing methodologies that incite the will to learn in students. Hence, a movement of teachers and researchers seeking to qualify the Sciences teaching and learning process is observed, especially in elementary school. In light of this need, added by the perception that methodologies used to teach this curricular component are having little effect as enablers in content appropriation, the present study seeks to develop, apply, and evaluate a didactic and methodological proposal based on the cognitive theory of Ausubel. More specifically, the work develops a Potentially Meaningful Teaching Unit (PMTU) for the topic of "respiratory system" in the final years of elementary school, so to analyze the relevance of the proposal regarding its feasibility as didactic strategy. The results of the study, revealed by the logbook, indicate the feasibility of the proposal, especially in terms of its potential for student engagement and questioning.
\end{abstract}

KEYWORDS: Potentially Meaningful Teaching Unit (PMTU). Theory of Significant Learning. Elementary school II. Respiratory system. 


\section{REFERÊNCIAS}

ALMEIDA, M. A., BARROSO, M., FALCÃO, E., GONZALEZ E. "Reversão do desempenho de estudantes em um curso de Física Básica". Revista Brasileira de Física, São Carlos-SP, v. 23, n. 1, p. 83-92, 2001.

ARRUDA, Sérgio de Mello; LABURÚ, Carlos Eduardo. Considerações sobre a função do experimento no ensino de ciências. In: NARDI, Roberto (Org.). Questões atuais no ensino de ciências. São Paulo: Escrituras, 1998. p. 53-60.

AUSUBEL, David P. Retenção e aquisição de conhecimentos: uma perspectiva cognitiva. Tradução de Lígia Teopisto. Lisboa: Plátano, 2003.

BORGES, Tarcisio. Novos rumos para o laboratório escolar de ciências. Caderno Brasileiro de Ensino de Física, v. 19, n. 3, p. 291-313, dez. 2002.

BRASIL. Ministério da Educação. Lei no 9.394, de 20/12/1996. Estabelece as diretrizes e bases da educação nacional. Disponível em:

<http://www.planalto.gov.br/ccivil_03/leis/19394.htm>. Acesso em: 31 mar. 2015.

. Parâmetros Curriculares Nacionais: Ciências Naturais - Ensino Fundamental. Brasília: MEC, 1998.

COPPETE, Maria Conceição. Diários de bordo e ensaios pedagógicos: possibilidades para pensar a formação de professores na modalidade de educação a distância. In: SEMINÁRIO INTERNACIONAL HISTÓRIA DO TEMPO PRESENTE, 2, 2014. Anais... Florianópolis, 2014.

LORENCINI, Álvaro Jr. O ensino de ciências e a formulação de perguntas e respostas em sala de aula. In: TRIVELATO, Silvia Luzi Frateschi (Org.). Coletânea Escola de Verão para professores de prática de ensino de Física, Química e Biologia. Serra Negra, SP: FEUSP, 1995. p. 105-114.

MOREIRA, Marco Antonio; MASINI. Teorias de aprendizagem. São Paulo: Editora Pedagógica Universitária, 1999.

.Ensino de Física no Brasil: Retrospectiva e Perspectivas. Revista Brasileira 
. Aprendizagem significativa crítica. 2010. Disponível em:

<http://www.if.ufrgs.br/ moreira/apsigcritport.pdf.> Acesso em: 15 jan. 2015.

Unidades de enseñanza potencialmente significativas. Aprendizagem

Significativa em Revista, v. 1, n. 2, p. 43-63, 2011.

NOVAK, Joseph D.; GOWIN, D. Bob. Aprender a aprender. Lisboa: Plátano Edições Técnicas, 1984.

PALÁCIOS, Christiane M; DAL'FARRA, Rossano A.; GELLER, Marlise. Concepções sistêmicas na educação ambiental: uma experiência com alunos do ensino fundamental. Revista Brasileira de Pesquisa em Educação em Ciências, v. 11, n. 1, p. 211- 229, 2011.

PINHO-ALVES, Jose. Atividades experimentais: do método à prática construtivista. 2000. Tese (Doutorado em Educação) - Universidade Federal de Santa Catarina, Florianópolis, 2000.

ROSA, Cleci T. Werner da. Laboratório didático de Física da Universidade de Passo Fundo: concepções teórico-metodológicas. 2001. Dissertação (Mestrado em Educação) - Universidade de Passo Fundo, Passo Fundo, 2001.

. A metacognição e as atividades experimentais no ensino de Física. 2011. Tese (Doutorado em Educação Científica e Tecnológica) - Universidade Federal de Santa Catarina, Florianópolis, 2011.

ZABALZA, Miguel. Diários de aula: um instrumento de pesquisa e desenvolvimento profissional. Porto Alegre: Artmed, 2004.

Recebido: 30 jul. 2016.

Aprovado: 09 nov. 2016.

DOI: $10.3895 /$ rbect.v9n3.4005

Como citar:

ROSA, C. T. W.; CAVALCANTI, J.; PEREZ, C. A. S Unidade de ensino potencialmente significativa para a abordagem do sistema respiratório humano: estudo de caso. Revista Brasileira de Ensino de Ciência e Tecnologia, v. 9, n. 3, 2016. Disponível em: <https://periodicos. utfpr.edu.br/rbect/article/view/4005>. Acesso em: $x x x$.

Correspondência:

Cleci Teresinha Werner da Rosa

Rua Uruguai, 1189/701, 99010-110 - Passo Fundo - Rio Grande do Sul

Direito autoral: Este artigo está licenciado sob os termos da Licença Creative Commons-Atribuição 4.0 Internacional. 